\title{
Anaesthetic management for hiatal hernia repair in a child with bartter's syndrome: A case report
}

Durriya Raza

Aga Khan University

Fauzia Khan

Aga Khan University, fauzia.khan@aku.edu

Follow this and additional works at: https://ecommons.aku.edu/pakistan_fhs_mc_anaesth

Part of the Anesthesiology Commons, and the Pediatrics Commons

\section{Recommended Citation}

Raza, D., Khan, F. (2020). Anaesthetic management for hiatal hernia repair in a child with bartter's syndrome: A case report. JPMA. The Journal of the Pakistan Medical Association, 70(4), 737-739.

Available at: https://ecommons.aku.edu/pakistan_fhs_mc_anaesth/385 


\section{Anaesthetic management for hiatal hernia repair in a child with Bartter's syndrome: A case report}

Durriya Raza, Fauzia Anis Khan

\begin{abstract}
Bartter syndrome is a rare disorder characterized by reduced sodium chloride transport in the distal nephrons of the kidney. Its clinical features are renal salt wasting, hypokalemic metabolic alkalosis, elevated renin and aldosterone levels with normal or low blood pressure, polyuria, hypercalciuria and malnutrition. The pathophysiologic and biochemical changes in these patients should be kept in mind when considering anaesthetic management. This case report describes our management in a nineteen months old, $3.6 \mathrm{~kg}$ weight male child with Bartter's syndrome who underwent elective repair of hiatal hernia and gastrostomy.
\end{abstract}

Keywords: Barter's syndrome, Hiatal hernia, Paediatric, Laparotomy.

\section{https://doi.org/10.5455/JPMA.302642254}

\section{Introduction}

Bartter syndrome is an autosomal recessive disorder with an estimated worldwide incidence of 1.2 per million people. ${ }^{1}$ It is an inherited tubulopathy characterized by markedly reduced sodium chloride transport in the distal nephrons. Although general review literature is available on pathogenesis, clinical manifestations and management but there are no controlled trials and only few case reports due to its low prevalence. 2,3 This case report describes our anaesthetic management of a child with this rare disorder.

\section{Case Report}

A 19 months old male child was scheduled for elective repair of hiatal hernia and gastrostomy following recurrent episodes of vomiting after oral feeds, in December 2014 at the Aga Khan University Hospital. He was born via Caesarean section at 29 weeks of gestation. After birth, he required ventilatory support because of respiratory distress. He was weaned off on the third day of life but remained in neonatal Intensive Care Unit (ICU) for one month. He had polyuria and recurrent episodes of

Department of Anaesthesiology, Aga Khan University, Karachi, Pakistan. Correspondence: Fauzia Anis Khan. Email:fauzia.khan@aku.edu hypokalaemia and was diagnosed as Bartter's Syndrome at the age of four months. He had his inguinal hernia repaired under general anaesthesia at the age of seven months.

At the time of presentation, he was malnourished and had failure to thrive and weighed only 3.6 kilograms. He had delayed milestones and could not sit without support. He was on oral potassium supplements. On examination, he was found to have hiatal hernia. His preoperative physical assessment revealed an irritable, malnourished child. His vital signs were as follows; heart rate: 135 breathsmin $^{-1}(70$ - 110), blood pressure: 100/54 $\mathrm{mm} \mathrm{Hg}$ (90-105/55-70), respiratory rate: 30 breathsmin ${ }^{-1}$ (20 - 30), oxygen saturation: $98 \%$ on room air. His laboratory investigations showed haemoglobin of 12.3 g/dL (10.9 - 15), WBC count: 14.9103/uL (6-17), sodium: $147 \mathrm{mEq} / \mathrm{L}$ (133-146), potassium: $3.1 \mathrm{mEq} / \mathrm{L}$ (3.7-5.2), chloride: $107 \mathrm{mEq} / \mathrm{Ln}(96-106)$, bicarbonate: $24.3 \mathrm{mEq} / \mathrm{L}$ (22-28). Blood urea nitrogen: $13 \mathrm{mg} / \mathrm{dl}$ (4-15), creatinine; $0.3 \mathrm{mEq} / \mathrm{L}$ (0.3- 0.7), magnesium: $3.1 \mathrm{mEq} / \mathrm{L}(1.8-2.5)$, and calcium: $9.1 \mathrm{mEq} / \mathrm{L}(<0.86)$. Barium study revealed hiatal hernia with moderate gastroesophageal reflux. His medications included oral potassium supplements, indomethacin $1.5 \mathrm{ml} 8$ hourly and Vitamin D supplements.

His medications were continued till surgery and an ICU bed was arranged. ECG, pulse oximeter and noninvasive blood pressure were applied before induction. General anaesthesia was planned with muscle relaxation and tracheal intubation after rapid sequence induction. Nasogastric tube was suctioned prior to induction with ketamine $2 \mathrm{mgkg}^{-1}$, succinylcholine $1.5 \mathrm{mg} \mathrm{kg}^{-1}$, and fentanyl 2 micrograms $\mathrm{kg}^{-1}$. Cricoid pressure was instituted and the trachea was intubated with a $3.5 \mathrm{~mm}$ uncuffed tracheal tube and bilateral equal air entry confirmed. His temperature was monitored via a nasopharyngeal temperature probe. Atracurium $0.5 \mathrm{mg} \mathrm{kg}^{-1}$ was administered on return of breathing. The patient remained stable throughout induction.

The surgeon inserted a Hickman's line in the right internal jugular vein. The child then underwent exploratory 
laparotomy with repair of hiatal hernia, pyloromyotomy and gastrostomy. Intraoperatively, he received oxygen and nitrous oxide 40:60, and isoflurane one Minimum Alveolar Concentration (MAC). His lungs were ventilated on pressure control mode and the inspiratory pressure was kept between 14-16 $\mathrm{cms} \mathrm{H}_{2} 0$. Muscle relaxation was maintained with atracurium boluses. Analgesia was augmented with paracetamol $50 \mathrm{mg}$ and two doses of fentanyl one microgram each. The patient remained stable throughout the procedure. His heart rate ranged from 130-155/min (90 -150 beats/ min), systolic blood pressure $75-95 \mathrm{~mm} \mathrm{Hg}(90-150 \mathrm{~mm} \mathrm{Hg})$, diastolic blood pressure $40-55 \mathrm{~mm} \mathrm{Hg}(55-65 \mathrm{~mm} \mathrm{Hg})$, and oxygen saturation $98-99 \%$. Total surgical time was three hours and bleeding was minimal. Patient was given a total of $85 \mathrm{ml}$ Ringers lactate solution during surgery. It was decided to keep the patient ventilated postoperatively.

He remained stable postoperatively in the paediatric intensive care and his trachea was extubated after eighteen hours. He was shifted from the ICU to the ward on second postoperative day. He remained stable in the ward and was discharged home on tenth postoperative day.

On follow-up after two months he gained $0.9 \mathrm{~kg}$ weight.

\section{Discussion}

Bartter's syndrome is characterized by reduction in salt absorption by the thick ascending limb of the loop of Henle. The characteristic features are renal salt wasting, hypokalaemic metabolic alkalosis, and elevated renin and aldosterone levels, with normal or low blood pressure. The syndrome has two clinical variants according to age of onset, Neonatal Classic Bartter syndrome. ${ }^{4}$ Neonatal Bartter syndrome is diagnosed immediately after birth. In the classic form, symptoms occur in the neonatal period or in infants aged two years or younger. Our patient was diagnosed with the classic variant of Bartter syndrome.

It is associated with maternal hydramnios and premature delivery which was present in our case. Symptoms started during the first two years of life and include polyuria, polydipsia, vomiting, constipation, salt craving, leading to dehydration, and failure to thrive. Short stature, as in our patient, is a common clinical manifestation. Chronic hypokalaemia, salt loss, polyuria, hypercalciuria, and malnutrition due to excessive water consumption and poor feeding leads to longitudinal growth retardation of bone in these children.

Guidelines for anaesthetic management have only recently been developed for perioperative management of people with salt wasting alkalosis. Due to lack of literature these are based on indirect evidence like case reports. ${ }^{3}$ Our report will add to this evidence.

Anaesthetic management in Bartter's syndrome poses many challenges. Cardiovascular instability, perioperative electrolyte and acid-base disturbances, and renal dysfunction are the concerning issues.

Major haemodynamic problems are generally not encountered in these patients. They are normotensive although they can lead to dehydration. Sodium chloride wasting and longtime treatment with potassium-sparing diuretics, spironolactone, are the common causes of hypovolaemia. Although our patient was not on beta blocker therapy but patients may be receiving these drugs and may have no chronotropic response in case of hypovolaemia. ${ }^{5}$ Haemodynamic parameters were stable throughout surgery in our patient.

Judicious management of electrolyte and acid-base status is important during the entire perioperative period. Bhaskar et al6 described the anaesthetic management of an eight years old child who underwent laparoscopic cholecystectomy without complications. They used rapid sequence induction with propofol, succinyl-choline, oxygen-nitrous oxide, vecuronium and sevoflurane and intermittent positive pressure ventilation (IPPV), along with infiltration of port sites with bupivacaine with standard monitoring. Kannan 7 and colleagues described the anaesthetic management of a child with Bartter's syndrome using caudal epidural analgesia for elective orchidopexy using bupivacaine $0.5 \%$. We induced anaesthesia with ketamine in contrast to other induction agents like propofol which can cause hypotension if the patient is hypovolaemic.

We avoided hyperventilation, as hypocapnia increases blood $\mathrm{pH}$ and lowers serum potassium further. Renal function of patients with Bartter's syndrome may influence the choice of the anaesthetic agents. Since elimination of volatile anaesthetics is independent of renal function, 4 isoflurane can be used safely. Our patient received isoflurane with no complications.

Anaesthetic management of these patients requires special focus on maintenance of cardiovascular stability, control of plasma potassium level and the prevention of renal damage. Anaesthetic technique should be 
individually tailored according to the surgical procedure and patient's clinical condition.

\section{Disclaimer: None.}

\section{Conflict of Interest: None.}

\section{Funding Disclosure: None.}

\section{References}

1. Nooh N, Abdullah W, Sheta S. Anesthetic management of a patient with Bartter's syndrome undergoing bilateral sagittal split osteotomy. Saudi J Anaesth. 2012; 6:419-22.

2. Emmett M, Elison DH. Bartter and Gitelman syndrome, Literature review. [Online] 2018. [Cited 2018 December 16]. Available from:
URL: $\quad$ www.uptodate.com/contents/bartter-and-gitelmansyndrome

3. Gallagher H, Soar J, Thomson C. New guidelines for perioperative management of people with inherited salt wasting alkalosis. $\mathrm{Br} \mathrm{J}$ Anaesth 2016; 116:746-9.

4. Akuma AO, Mittal SK, Sambo AA. Neonatal Bartter syndrome associated with ileal atresia and cystic fibrosis. Indian J Nephrol 2013; 23: 47-50.

5. Roelofse, JA, van der Westhuijzen AJ. Anaesthetic management of a patient with Bartter's syndrome undergoing orthognathic surgery. Anesth Prog. 1997; 44: 71-5.

6. Bhaskar BS, Rao G, Joshi SB, Arun S, Ajay S. Anaesthesia for laparoscopic cholecystectomy in Bartter's syndrome. Indian J Anaesth. 2010; 54: 327-30.

7. Kannan S, Delph Y, Moseley HS. Anaesthetic management of a child with Bartter's syndrome. Can J Anaesth. 1995; 42: 808-12. 